\title{
Electron microscopic study of association between Helicobacter pylori and gastric and duodenal
}

\section{mucosa}

\author{
L A Noach, T M Rolf, G N J Tytgat
}

\begin{abstract}
Aim-To study the ultrastructural appearances of Helicobacter pylori in antral and duodenal biopsy specimens and its relation with the epithelial cells. Methods-Endoscopically obtained antral and duodenal biopsy specimens were examined using transmission electron microscopy and freeze fracture analysis. Results-Most bacteria looked curved, but in the duodenal bulb coccoid bacteria were relatively common. Bacteria were often found around intercellular junctions. Freeze fracture examination indicated abnormalities of the tight junction complexes in patients with $\boldsymbol{H}$ pylori infection. In many biopsy specimens bacteria were seen closely attached to the epithelial cell membrane by different forms of adhesion. In addition to what looked like intracytoplasmic penetration by bacteria, several examples of genuine penetration were observed.

Conclusion-H pylori is commonly found adhering to epithelial cells. Occasionally, $H$ pylori may also penetrate cells. These features may contribute to the pathogenic action of the organism.
\end{abstract}

(F Clin Pathol 1994;47:699-704)

Helicobacter pylori is ubiquitous and its presence in the stomach and duodenal bulb is strongly associated with gastritis, duodenitis, and peptic ulcers. ${ }^{1-3}$

The usual appearance of $H$ pylori in vivo is that of a curved or S-shaped Gram negative rod with several sheathed flagella. ${ }^{45} \mathrm{Next}$ to spiral-shaped organisms, coccoid forms have occasionally been described. ${ }^{4-6}$ In a previous study these forms were predominantly found in the duodenal bulb. ${ }^{4}$ However, other investigators did not find evidence for a specific distribution pattern. ${ }^{56}$ As yet, it is not clear whether these forms reflect degenerative alterations or adaptations to marginal or hostile environments with the capacity for regrowth. ${ }^{4-6}$

$H$ pylori is well adapted for residence within or beneath the mucus layer of the stomach. For reasons unknown, the area around intercellular tight junctional complexes seems to be a preferred site. ${ }^{4-11}$ A striking feature of $H$ pylori is its exclusive relation to cells derived from gastric-type mucosa. The physicochemical properties of the mucus overlying gastric- type cells may be responsible for this phenomenon. ${ }^{6}$

Although most $H$ pylori are found in the mucus layer, a considerable proportion adhere to epithelial cells. ${ }^{4811-16}$ Adhesion is considered to be an important aspect of bacterial pathogenicity. ${ }^{1217}$ Evidence shows that adherence affords advantage for toxin-producing organisms and induces degeneration of microvilli, degeneration of the cytoskeleton with actin polymerisation, depletion of mucus granules, and an increase in sialic acid-rich glycoproteins in the apical part of the cytoplasm. ${ }^{4121418}$ Some investigators have also suggested a direct relation between the proportion of adhesion sites and the histological grade of epithelial degeneration. ${ }^{12}$

Controversy exists over whether $H$ pylori is also capable of invasion into epithelial cells. Internalisation of $H$ pylori by HEp-2 cells in vitro has been observed. ${ }^{19}$ In vivo, apart from phagocytosed organisms in neutrophils, intracellular bacteria have been detected only incidentally in intracytoplasmic vacuoles, in lysosomes and closely related to such structures. ${ }^{4131520-22}$ In one study intracytoplasmic $H$ pylori was reported to be present in duodenal mucosa in $10 \%$ of patients with duodenal ulceration. ${ }^{413}$ In contrast, several other authors did not find any evidence for invasiveness or internalisation..$^{59101423}$

\section{Methods}

Antral and duodenal mucosal biopsy specimens were obtained during upper gastrointestinal endoscopy from 27 patients (16 men, 11 women; mean age 55 years, range 20-79 years) with dyspeptic complaints and $H$ pylori infection. The presence of $H$ pylori was assessed by culture and histological examination of antral biopsy specimens.

For transmission electron microscopy, biopsy specimens from the antrum and duodenal bulb were immediately fixed in McDowell's solution. The specimens were postfixed in $1 \%$ osmium tetroxide and dehydrated through an ethyl alcohol sequence until alcohol reached $90 \%$. The tissue was embedded in Epon 812 and $1 \mu \mathrm{m}$ sections were stained with Richardson's stain. Areas of interest were selected, trimmed, and cut with a diamond knife into sections of about $600 \times 10^{-1} \mathrm{~nm}$ for transmission electron microscopy. These sections were stained with Reynold's lead citrate and uranyl magnesium acetate. Ultrastructural examinations were

L A Noach

G N J Tytgat

Correspondence to:

Dr L A Noach 
performed using a Philips 300 electron microscope at an accelerating voltage of 60 kilovolts.

In some preparations, ruthenium red was added to the fixation fluid to stabilise surface polysaccharides.

The distribution of coccoid forms and curved or spiral forms of $H$ pylori in stomach and duodenum was studied in biopsy specimens from five patients from whom we obtained additional tissue from the duodenal bulb.

Adhesion sites were studied in transmission electron micrographs of antral mucosa from 27 patients. Adhesion was defined as a close attachment between bacteria and epithelial cells, such that virtually no space was visible between them using transmission electron microscopy. On the basis of morphological appearances, the different types of interaction of the organism with the epithelial cells were categorised into five groups: (1) with raised plasma membrane forming an adhesive pedestal; (2) occupying depressions in the plasma membrane; (3) abutting on to the plasma membrane; (4) fusion of bacterial and plasma membrane with dissolution of membranes; (5) internalisation in cytoplasm.

The numbers of adherent organisms were counted and the prevalence and relative frequency of each type of adhesion was calculated.

In biopsy specimens from three patients freeze fracture analysis was performed to investigate the membrane ultrastructure of $H$ pylori and to examine the structure of the intercellular tight junction complexes.

Before freezing the tissue had been fixed in $2.5 \%$ glutaraldehyde in $0.1 \mathrm{M}$ phosphate

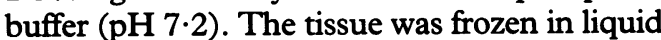
propane $\left(-196^{\circ} \mathrm{C}\right)$, fractured at $-100^{\circ} \mathrm{C}$ (Balzer's freeze-etch unit), shadowed with platinum carbon, and then digested in filtered commercial bleach. The replicas were washed three times in distilled water, mounted on

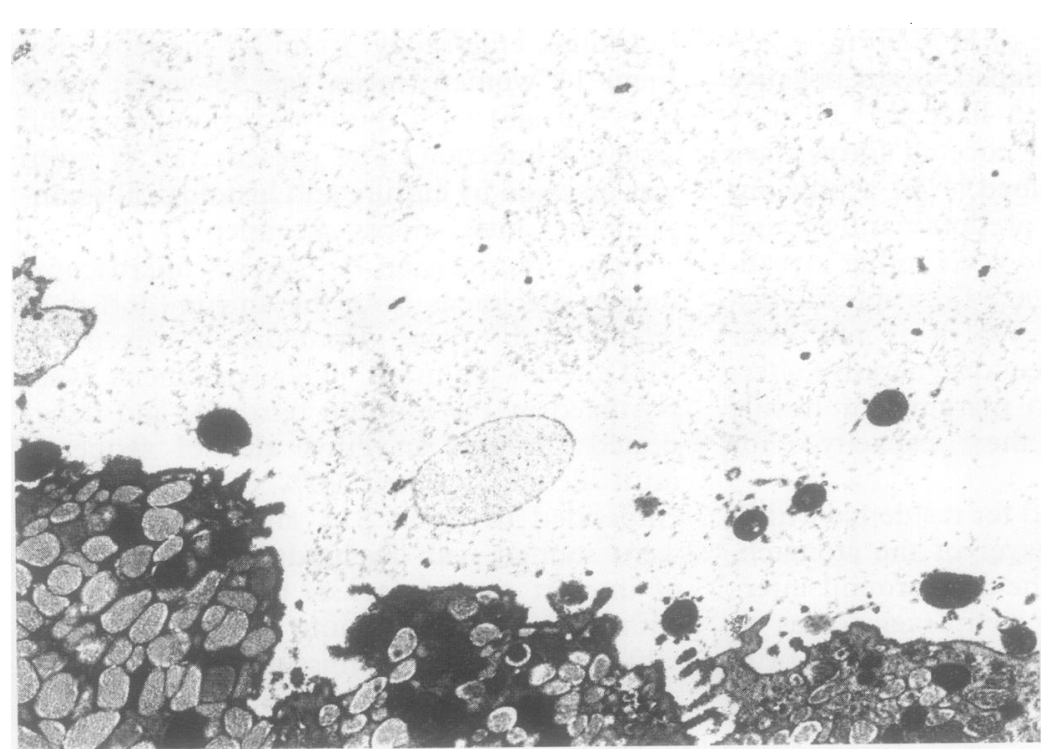

Figure 1 Multiple organisms in the duodenal bulb exhibiting a coccoid appearance. grids, and examined in a Philips 300 electron microscope.

\section{Results}

In all biopsy specimens curved as well as coccoid micro-organisms were observed. Of the total number of $H$ pylori organisms counted in biopsy specimens from five patients, from whom specimens from both duodenum as well as stomach were obtained, $13(17 \%)$ of the microbial structures in antral biopsy specimens, and $24(35 \%)$ in duodenal specimens were coccoid in appearance (fig 1).

Investigation of the internal appearance of $H$ pylori by freeze fracture analysis showed that the organism was surrounded by a cytoplasmic membrane, which, in turn, was covered by an outer membrane (fig 2). Both the outer and inner face of the two membranes were covered with dot-like structures, presumably corresponding to incorporated proteinaceous structures.

Preliminary freeze fracture analysis in two additional patients with $H$ pylori infection and one $H$ pylori negative patient was suggestive of damage of the junctional strands in the

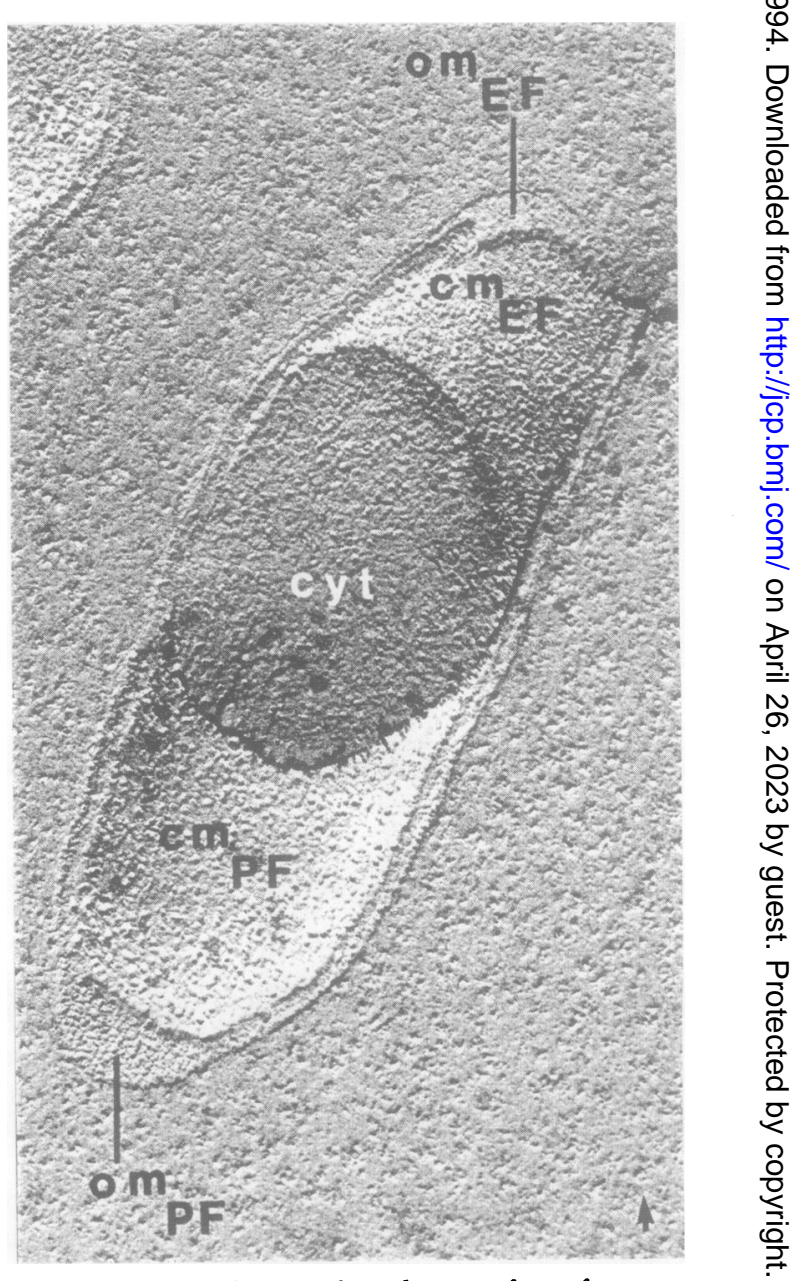

Figure 2 Freeze fracture of membrane surfaces of $H$ pylori showing the cytoplasm (cyt) surrounded by the cytoplasmic membrane $(\mathrm{cm})$. The fracture face of the half of the cytoplasmic membrane associated with the protoplasm is referred to as the protoplasmic face (PF) and the half facing' the extracellular matrix as the extracellular face $(E F)$. 


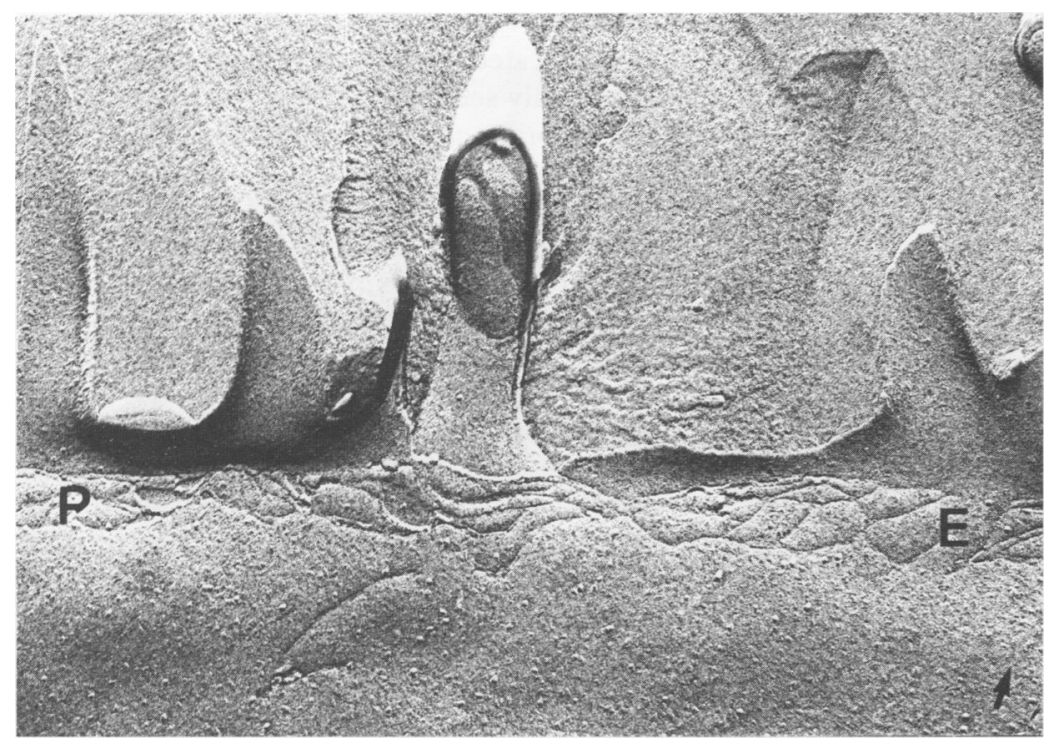

Figure 3 Freeze fractured tight junctional complex in biopsy specimen from $H$ pylori negative patient showing band of clearly delineated interconnecting ridges on $P$ fracture face $(P)$ and grooves on $E$ fracture face $(E)$.

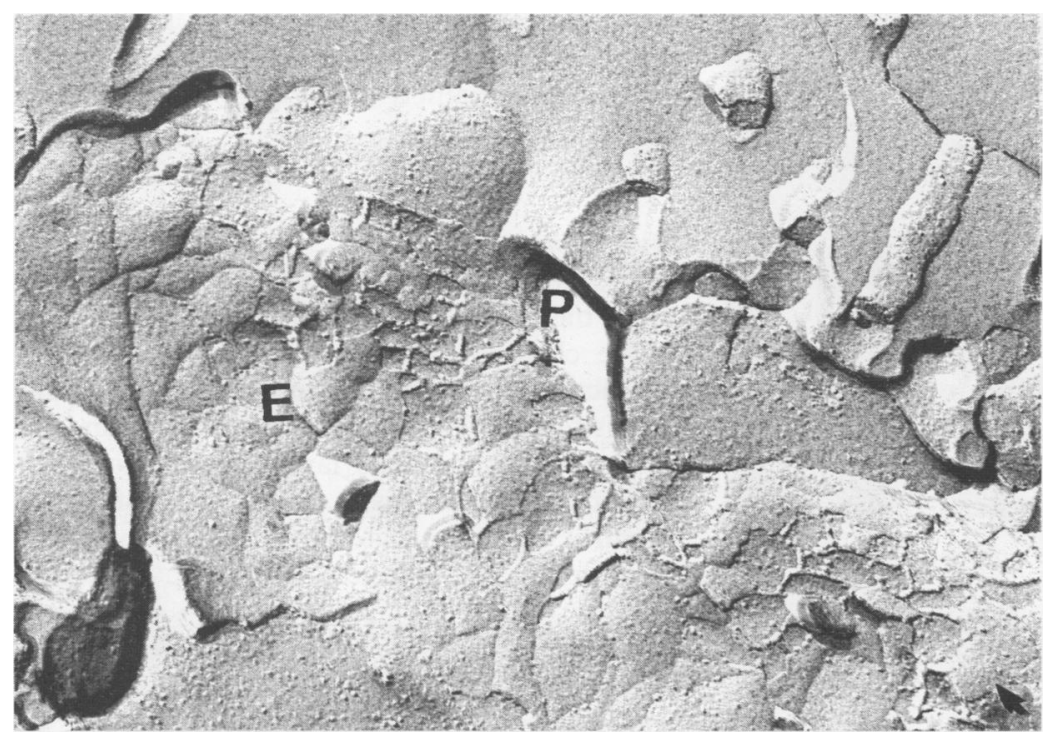

Figure 4 Freeze fracture appearance of a tight junction complex in antral biopsy specimen from a patient with $H$ pylori infection showing irregular and sometimes disrupted ridges on fracture face $P(P)$ and irregular grooves on fracture face $E(E)$.

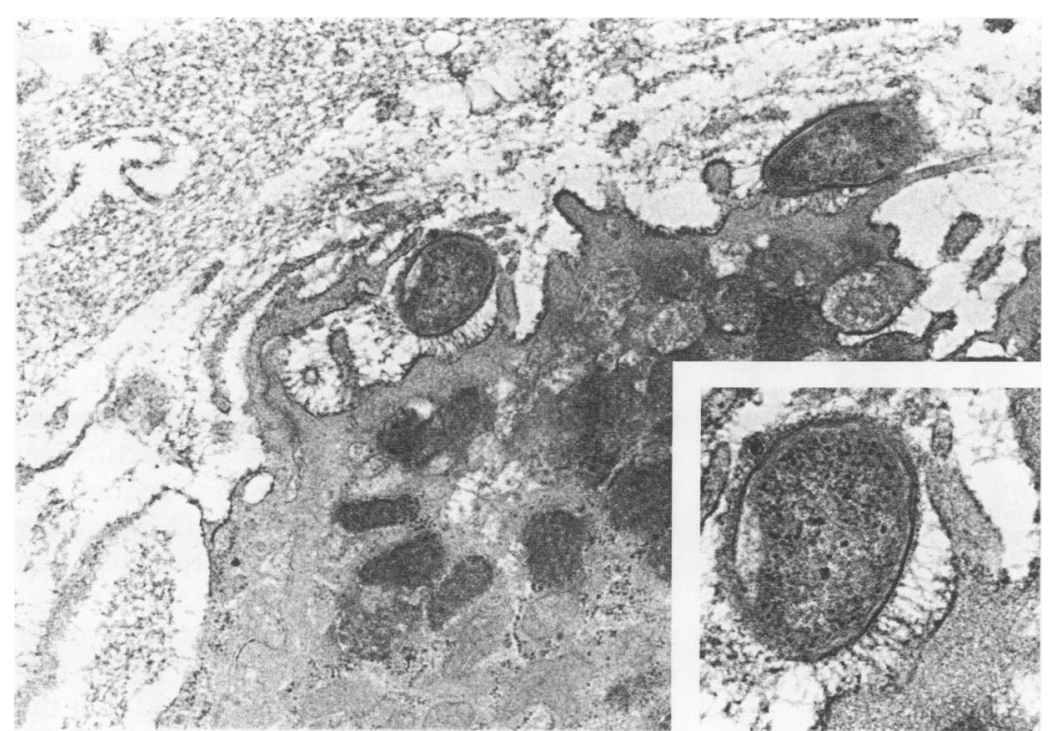

Figure 5 Filamentous strands between bacterial membrane and cytoplasmic membranes.
$H$ pylori positive cases (figs 3 and, 4). In contrast to the normal delicate network of interconnecting protein strands in the $H$ pylori negative patient, the tight junctional structure appeared irregular, thickened, knobby and focally fragmented in the patients with $H$ pylori associated gastritis.

At transmission electron microscopy, most $H$ pylori organisms in the antrum were seen scattered in the mucus layer or positioned close to the microvillous surface without membrane-to-membrane attachment with the epithelial cells. Sometimes organisms along the surface epithelium were orientated into parallel arrays but, in general, organisms showed no preferential orientation. Moreover, many bacteria were present in the gastric pits. The immediate vicinity of intercellular junctions appeared to be a favoured site.

The presence of $H$ pylori was sometimes, but not always, associated with depletion of microvilli and mucin granules. Strands of filamentous material were readily observed projecting from the bacterial surface towards the epithelial luminal membrane (fig 5). This attachment probably involves interaction between surface polysaccharides (glycocalyx) mediated by lectin binding. ${ }^{5}$

Apart from abundant bacteria in the mucus layer, without intimate contact with the epithelial cell membrane, adherent organisms were detected in $23(85 \%)$ out of 27 infected patients whose antral biopsy specimens were investigated.

The table shows the prevalence of the different types of adhesion and internalisation formed by 231 organisms in these 23 patients.

Plateau-like extrusions of the epithelial cell or adhesive pedestals were seen in seven (30\%) patients. Occasionally, pedestal formation was found at more than one site between one bacterium and the cell surface (fig 6). At sites of intimate contact, the plasma membrane was usually devoid of microvilli and of glycocalyx-like material. Other closely adherent organisms were seen occupying depressions in the plasma membrane. The most frequently observed form of adhesion was the abutting type. With this type, the contour of the epithelial membrane at the point of contact with the organism appeared unaltered, apart from loss of microvilli. Usually, adhesion was accompanied by degenerative changes in the adjacent cytoplasm consisting of a more translucent area and disruption of the cytoskeletal elements.

At other sites, a picture suggesting partial membrane fusion between the outer membrane of bacteria and the epithelial plasma

Relative frequency of each form of adhesion and of internalisation

\begin{tabular}{lc}
\hline Type of adhesion & $n(\%)$ \\
\hline Adhesive pedestals & $19(8)$ \\
Membrane depressions & $26(11)$ \\
Abutting adhesion & $164(71)$ \\
Membrane fusion & $16(7)$ \\
Internalisation & $6(3)$ \\
\hline
\end{tabular}




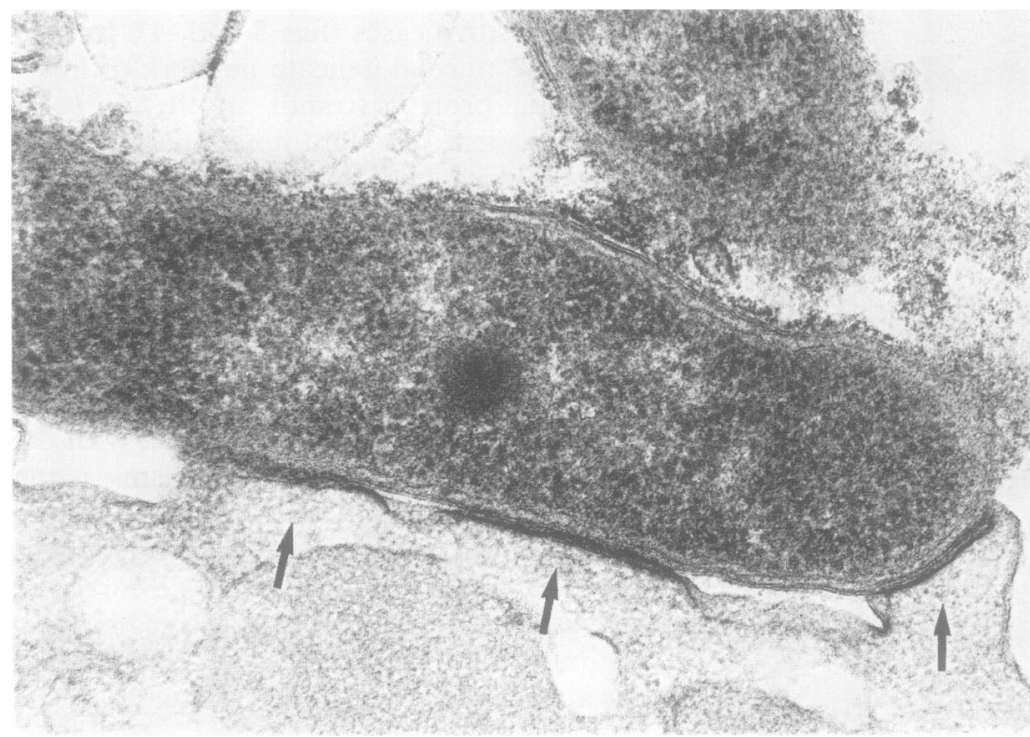

Figure 6 Multiple adhesion pedestals (arrows) between cell and one organism.

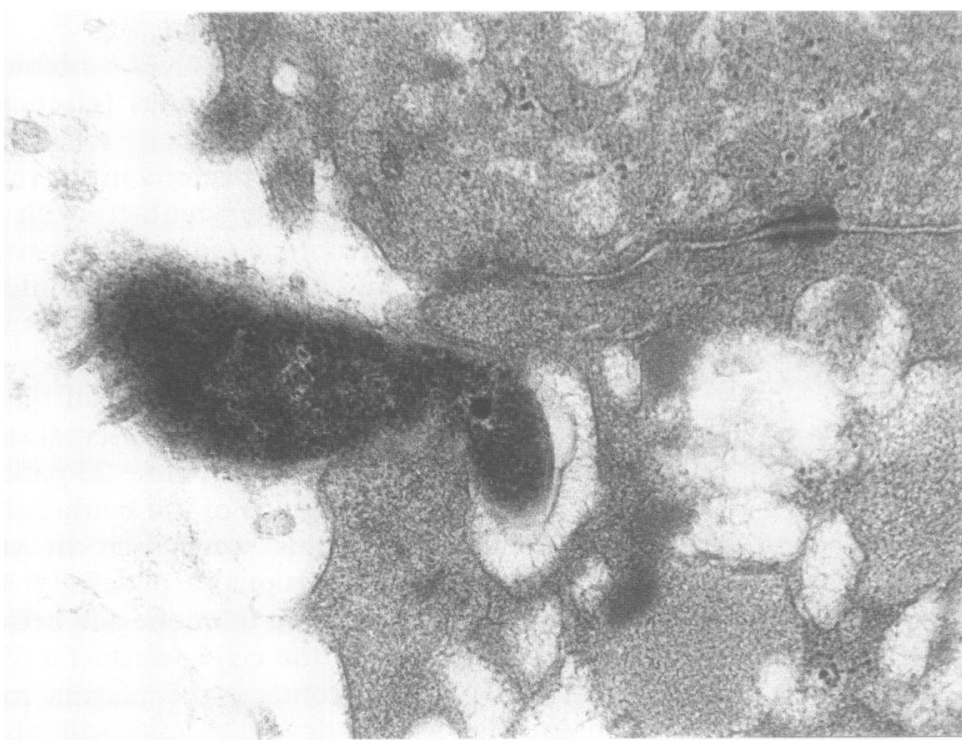

Figure $7 \quad H$ pylori partly attached by filamentous strands and impinging on the luminal cell membrane and engulfment suggesting an attempt at intracytoplasmic penetration. Note apparent deformation of luminal cell membrane and bacterium.

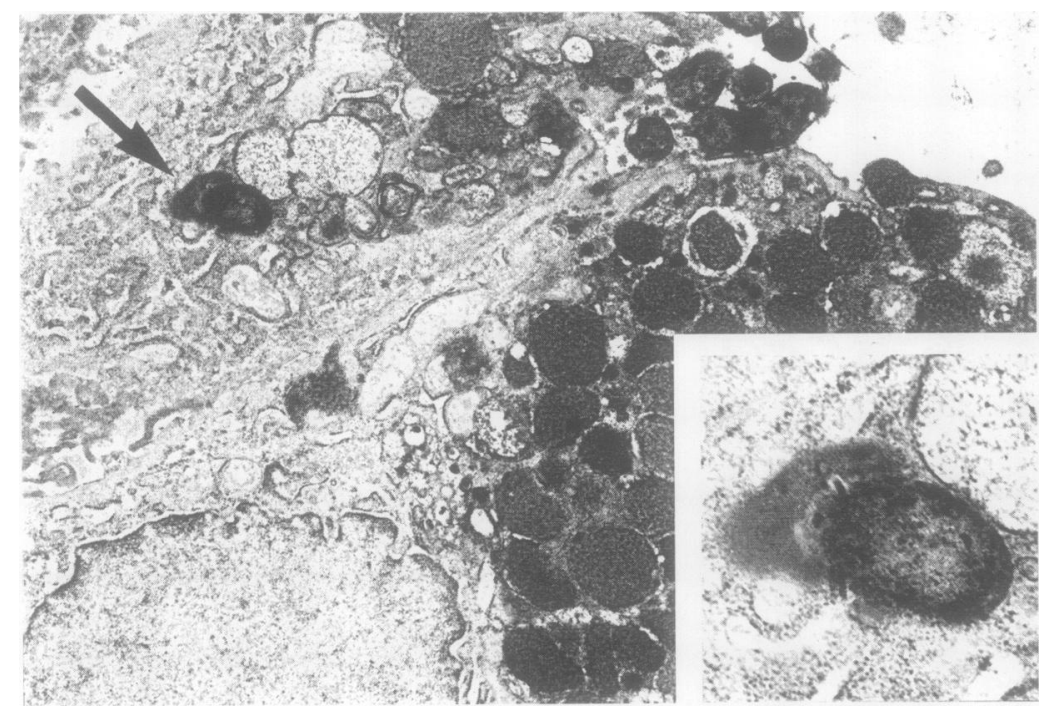

Figure 8 Highly suggestive example of true intracytoplasmic penetration of $H$ pylori (arrow). membrane was observed. Moreover, images that suggested intracellular engulfment were occasionally seen (fig 7).

In accordance with previous findings intracellular cystic spaces filled with granular material were occasionally found. ${ }^{1216}$ Such alterations are perhaps the morphological expression of cytotoxin-induced vacuolisation of the cytoplasmic structures. ${ }^{12}$

Images mimicking intracytoplasmic penetration were seen in several cases. At higher magnifications, filamentous strands were sometimes visible between the bacterial and cytoplasmic membrane. Tangential sectioning may have been responsible for such confusing images. Yet early internalisation cannot be ruled out. Indeed, after an extensive search, six examples were found (in four patients) which were highly suggestive of true internalisation (fig 8).

Images of apparent deep penetration into the intercellular space were readily visualised but appeared instead to be due to excessive ballooning of the apex of the surface mucus cells. These images created a misleading impression of deep penetration whereas the organism remained superficial to the tight junction area (fig 9).

\section{Discussion}

There is substantial clinical evidence that $H$ pylori has a causal role in the development of active chronic gastritis. ${ }^{13} \mathrm{H}$ pylori has many characteristics which are considered to be prerequisites for pathogenicity: motility in the viscous gastric mucus layer; production and elaboration of urease; production of other harmful enzymes, cytokines, and toxins; and its potency of adhesion to gastric epithelial cells. ${ }^{4-9} 111214$

Ultrastructurally, $H$ pylori looks like a curved or S-shaped organism with a length of about $3 \mu \mathrm{m}$ and a width of about $0.5 \mu \mathrm{m}$. In accordance with previous observations, we also found coccoid-shaped bacteria in duodenum and antrum..$^{4-6}$ It should be emphasised that these observations were based on a small number of biopsy specimens. Moreover, with transmission electron microscopy it is impossible to define three-dimensional shapes and the number of coccoid forms may have been overestimated due to cross-sectioning of curved bacteria. However, our finding that the percentage of organisms with a coccoid profile is seen more often in the duodenum than in the stomach, and that some duodenal biopsy specimens exclusively showed coccoid-shaped $H$ pylori, may indicate that the duodenal milieu somehow predisposes to coccoid transformation or that coccoid organisms are transported preferentially from the stomach. Why the duodenal bulb may be a preferential site for coccoid transformation is still not clear and a matter of debate. Also the question whether the coccoid form of $H$ pylori represents a degenerative or a non-viable form or only a (temporary) dormant state needs further clarification. Jones et al suggested that the coccoid structure assists the survival of the 


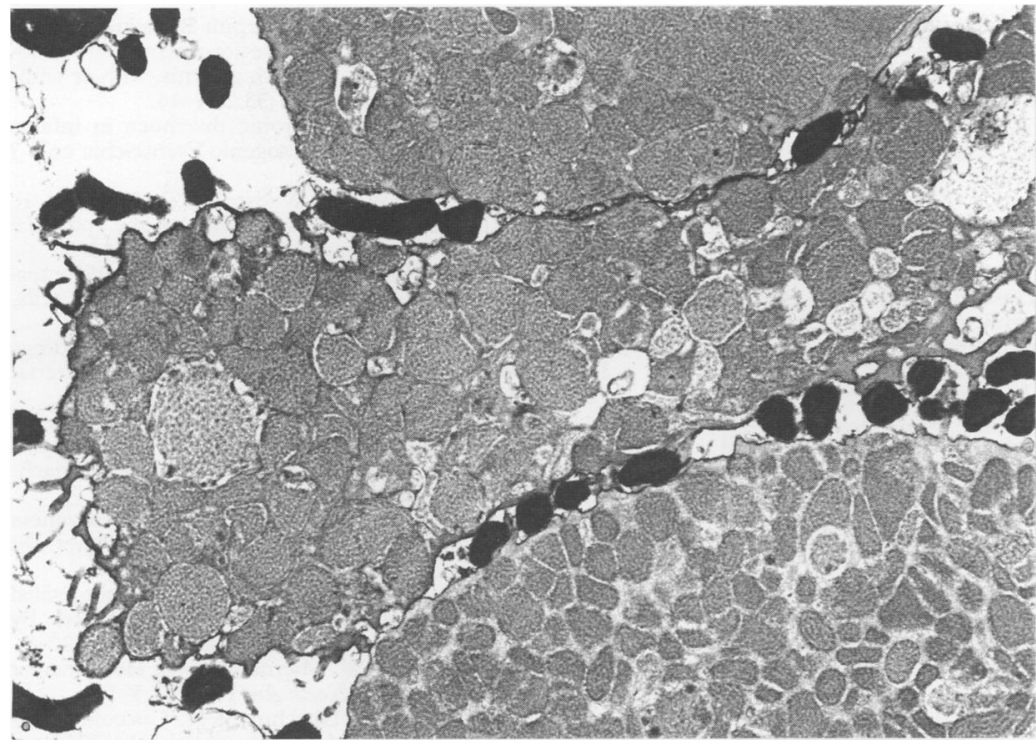

Figure 9 Ballooning of surface mucus secreting cells with numerous organisms entering between the cells. Despite seemingly deep penetration, organisms still remain superficial to the area of the tight junction.
A more stable form of interaction concerns the formation of adherence pedestals. Such pedestals are similar to those formed by enteropathogenic Escherichia coli. ${ }^{17}$ At other sites, organisms abut on to the epithelial plasma membrane or occupy depressions in the plasma membrane, or presumably attempt to penetrate cells. Whether the different morphological features of adhesion represent different stages of attachment which will ultimately end in intracytoplasmic penetration or engulfment has still to be elucidated.

Adhesion is generally associated with effacement of microvilli and disruption of cytoskeletal elements. ${ }^{414}$ According to some authors, evidence of intraepithelial degeneration is commonly observed. They have described distortion of the plasma membrane, dissolution of mucus granules, increased generation of sialic acid-rich glycoproteins, and the appearance of intracytoplasmic vacuoles and abundant phagolysosomes. ${ }^{4} 111216$ The production of a vacuolating cytotoxin by $H$ pylori may be responsible for the often observed vacuolation. ${ }^{32}$ In one study the presence of epithelial degeneration was associated with a significantly increased proportion of adhering $H$ pylori. ${ }^{12}$ Apart from loss of mucus granules resulting in a translucent emptylooking structure, and occasionally disruption of the plasma membrane, we found no other ultrastructural evidence of intracellular degeneration. It has still to be clarified whether the aforementioned degenerative changes are induced by adhesion of $H$ pylori per se or whether $H$ pylori preferentially adheres to damaged cells.

In several studies $H$ pylori was mentioned as being non-invasive or as penetrating epithelial cells only rarely..$^{5101423}$ In contrast, Bode et al stated that intracellular organisms could be found in the gastric metaplastic cells in $10 \%$ of patients with active duodenal ulcer. ${ }^{13}$ In vitro, intracellular uptake of $H$ pylori has been shown to occur by receptor-mediated endocytosis. ${ }^{19}$ Until now, a limited number of studies have shown unequivocally internalised $H$ pylori in gastric epithelial cells in vivo. 813152122 In agreement with previous studies, we found that $H$ pylori is predominantly an extracellular organism, either living in or beneath the mucus layer or attached to the epithelial cells. Although transmission electron micrographs sometimes suggest internalisation, images may be confusing and may not always reflect genuine intracytoplasmic localisations. Artefacts due to tangential section may have been responsible for some of the confusing images. However, other pictures unequivocally indicate that, although rare, intracellular penetration can occur.

Our observations of intimate contact between $H$ pylori and gastric epithelial cells, including internalisation, agree with earlier findings and also suggest that these may be important features of the pathogenic action of this organism. Further studies are needed to elucidate the exact mechanism of adhesion, intracellular invasion, and degenerative alterations. adhesins have been reported to be involved in the interaction with the mucosal cell receptor. ${ }^{3031}$

Initial adhesion is thought to be represented by the formation of a glycocalyx and probably involves a non-specific interaction. ${ }^{6}$ 
1 Marshall BJ, Armstrong JA, McGechie DB, Glancy RJ. Attempt to fulfil Koch's postulates for pyloric Campylobacter. Med F Aust 1985;142:436-43.

2 Tytgat GNJ, Axon ATR, Dixon MF, Graham DY, Lee A, Marshall BJ. Helicobacter pylori, causal agent in peptic ulcer disease? In: Working Party Report of the World Congresses of Gastroenterology, 26-31 August 1990 Congresses of Gastroenterology, 26-31 August 1990,
Sydney, Australia. Oxford: Blackwell Scientific Sydney, Australia. Ox

3 Tytgat GNJ, Noach LA, Rauws EAJ. Helicobacter pylori. Eur f Gastroenterol Hepatol 1992;4(suppl 1):S7-S15.

4 Bode G, Malfertheiner P, Ditschuneit $H$. Pathogenetic implications of ultrastructural findings in Campylobacter pylori related gastroduodenal disease. Scand Gastroenterol 1988;23(suppl 142):25-39.

5 Jones DM, Curry A. The ultrastructure of Helicobacter pylori. In: Rathbone BJ, Heatley RV, eds. Helicobacter pylori and gastroduodenal disease. Oxford: Blackwell pylori and gastroduodenal disease.

6 Steer HW. Ultrastructure of Helicobacter in vivo. In: Rathbone BJ, Heatley RV, eds. Helicobacter pylori and gastroduodenal disease. Oxford: Blackwell Scientific Publications, 1992:42-50.

7 Caselli M, Figura N, Trevisani L, Pazzi P, Guglielmetti $P$, Bovolenta $\mathrm{R}$, et al. Patterns of physical modes of contact between Campylobacter pylori and gastric epithelium: implications about the bacterial pathogenicity. $\mathrm{Am} \mathcal{f}$ Gastroenterol 1989;84:511-3.

8 Kazi JL, Sinniah R, Zaman V, Ng ML, Jafarey NA, Alam SM, et al. Ultrastructural study of Helicobacter pyloriassociated gastritis. $\mathcal{F}$ Pathol 1990;161:65-70.

9 Hazell SL, Lee A, Brady L, Hennessy W. Campylobacter pyloridis and gastritis: association with intercellular pyloridis and gastritis: association with intercellular
spaces and adaptation to an environment of mucus as spaces and adaptation to an environment of mucus as
important factors in colonization of the gastric epithelium. F Infect Dis 1986;153:658-63.

10 Rauws EAJ. Campylobacter pylori. Thesis. Amsterdam: Den Ouden, WC. 1989:49-77

11 Chen XG, Correa P, Offerhaus J, Rodriguez E, Janney F, Hoffmann E, et al. Ultrastructure of the mucosa harboring Campylobacter-like organisms. Am $\mathcal{f}$ Clin Pathol 1986;86:575-82.

12 Hessey SJ, Spencer J, Wyatt JI, Sobala G, Rathbone BJ, Axon ATR, et al. Bacterial adhesion and disease activity in Helicobacter associated chronic gastritis. Gut 1990; in Helicobac

13 Bode G, Malfertheiner P, Ditschuneit $H$. Invasion of Campylobacter-like organisms in the duodenal mucosa in patients with active duodenal ulcer. Klin Wochenschr 1987;65:144-6.

14 Thomsen LL, Gavin JB, Tasman-Jones C. Relation of Helicobacter pylori to the human gastric mucosa in chronic gastritis of the antrum. Gut 1990;31:1230-6.

15 Tricottet V, Bruneval P, Vire $O$, Camilleri JP. Campylobacter-like organisms and surface epithelium abnormalities in active, chronic gastritis in humans: an abnormalities in active, chronic gastritis in humans: an
ultrastructural study. Ultrastruct Pathol 1986;10:113-22.
16 Fiocca R, Villari L, Turpini F, Turpini R, Sokia E. High incidence of campylobacter-like organisms in endoscopic biopsies from patients with gastritis, with or without peptic ulcer. Digestion 1987;38:234-44.

17 Clausen CR, Christie DL. Chronic diarrhoea in infants caused by adherent enteropathogenic Escherichia coli. $\mathcal{F}$ caused by adherent enteropatr 1982;100:358-61.
Pedian

18 Brassens-Rabbé MP, Wu S, Wadström T, Mégraud F. Effect of Helicobacter pylori adherence on the epithelial cell skeleton. Ir F Med Sci 1992;161(suppl 10):42-3.

19 Evans DG, Evans DJ, Graham DY. Adherence and internalization of Helicobacter pylori by HEp-2 cells Gastroenterology 1992;102:1557-67.

20 Meyrick-Thomas J, Poynter D, Goodling C, Woodings DF, Selway S, Cook AR, et al. Gastric spiral bacteria. Lancet 1984;ii: 100 .

21 Lee WK, Gourley WK, Buck GE, Subramanyam K. A light and electron microscopic study of a Campylobacter-like bacteria inhabiting the human stomach. Gastroenterology 1985;88:1470.

22 Andersen LP, Holck S. Possible evidence of invasiveness of Helicobacter pylori. Eur $\mathcal{F}$ Clin Microbiol Infect Dis 1990;9:135-8.

23 Sirigu F, Capeccioni PS, Dessi A, Usai P. Morphological study of the gastric antral mucosa colonized by Campylobacter pylori. Ital f Gastroenterol 1990;22:22-3.

24 Goodwin CS, Worsley BW. Microbiology of Helicobacter pylori. Gastroenterol Clin North Am 1993;22:5-19.

25 Bode G, Malfertheiner P, Ditschuneit H. Coccoid forms of $\mathrm{H}$ pylori are viable. Ital $\mathcal{F}$ Gastroenterol 1991;23(suppl 2):35-6.

26 Kiehlbauch JA, Albach RA, Baum LI, Chang KP. Phagocytosis of Campylobacter jejuni and its intracellular survival in mononuclear phagocytes. Infect Immun 1985;48:446-51.

27 Ogg JE. Studies on the coccoid form of ovoid Vibrio fetus I Cultural and serological investigations. Am $\mathcal{f}$ Vet Res 1962;23:354-8.

28 Ohkusa $T$, Yamamoto $M$, Kataoka K, Kyoi T, Ueda F, Fujimoto $\mathrm{H}$, et al. Electron microscopic study of intercellular junctions in human gastric mucosa with special reference to their relationship to gastric ulcer. Gut 1993;34:86-9.

29 Posalaky Z, Posalaky I, McGinley D, Meyer RA. The gastric mucosal barrier: tight junction structure in gastritis and ulcer biopsies. Virchows Arch Pathol Anat 1989, 414:217-22.

30 Evans DG, Evans DJ, Moulds J, Graham DY. N-acetylneuraminyl-lactose-binding fibrillar hemagglutinin of Campylobacter pylori: a putative colonization factor antigen. Infect Immun 1988;56:2896-906.

31 Dunn BE. Pathogenic mechanisms of Helicobacter pylori. Gastroenterol Clin North Am 1993;22:43-57.

32 Leunk RD, Johnson PT, David BC, Kraft WG, Morgan DR. Cytotoxic activity in broth-culture filtrates of Campylobacter pylori. $f$ Med Microbiol 1988;26: 93-9. 